BNL-73619-2005-CP

\title{
Polarized Hydrogen Jet Target for Measurement of RHIC Proton Beam Polarization
}

T. Wise, M. Chapman, W. Haeberli (U. Wisconsin-Madison)

D. Graham, A. Kponou, G. Mahler, Y. Makdisi, W. Meng, A. Nass, J. Ritter, A. Zelenski (BNL)

S. Kokhanovski and V. Zubets (INR, Russia)

Presented at $16^{\text {th }}$ International SPIN Physics Symposium

Trieste, Italy, October 10-16, 2004

January 2005

Collider-Accelerator Department

Brookhaven National Laboratory

P.O. Box 5000

Upton, NY 11973-5000

www.bnl.gov

Managed by

Brookhaven Science Associates, LLC

for the United States Department of Energy under

Contract No. DE-AC02-98CH10886 


\section{DISCLAIMER}

This report was prepared as an account of work sponsored by an agency of the United States Government. Neither the United States Government nor any agency thereof, nor any of their employees, nor any of their contractors, subcontractors, or their employees, makes any warranty, express or implied, or assumes any legal liability or responsibility for the accuracy, completeness, or any third party's use or the results of such use of any information, apparatus, product, or process disclosed, or represents that its use would not infringe privately owned rights. Reference herein to any specific commercial product, process, or service by trade name, trademark, manufacturer, or otherwise, does not necessarily constitute or imply its endorsement, recommendation, or favoring by the United States Government or any agency thereof or its contractors or subcontractors. The views and opinions of authors expressed herein do not necessarily state or reflect those of the United States Government or any agency thereof. 


\title{
POLARIZED HYDROGEN JET TARGET FOR MEASUREMENT OF RHIC PROTON BEAM POLARIZATION
}

\author{
T. WISE, M. CHAPMAN, W. HAEBERLI
}

University of Wisconsin, Madison, WI 53706 *

D. GRAHAM, A. KPONOU, G. MAHLER, Y. MAKDISI, W. MENG, A. NASS, J. RITTER, A. ZELENSKI

Brookhaven National Laboratory, Upton, NY 11973, USA

S. KOKHANOVSKI, V. ZUBETS

INR, Moscow, Russia

\begin{abstract}
The performance and unique features of the RHIC polarized jet target and our solutions to the important design constraints imposed on the jet by the RHIC environment are described. The target polarization and thickness were measured to be $0.924 \pm 2 \%$ and $1.3 \pm 0.2 \times 10^{12}$ atoms $/ \mathrm{cm}^{2}$ respectively.
\end{abstract}

\section{Introduction}

The jet target was installed into the RHIC beam line for the polarized proton run in spring 2004. During this time the source produced a highly polarized gas target with record thickness for a polarized jet. We required vertical target polarization with a strong $(0.12 \mathrm{~T})$ and uniform $(\gamma \mathrm{B} / \mathrm{B}<$ $\left.5^{*} 10^{-3}\right)$ vertical guide-field. The field uniformity is necessary to avoid depolarizing bunch field induced resonances from the circulating RHIC beam. The source, see Fig. 1, is mounted vertically to allow freedom in the midplane for recoil particle detection near $90^{\circ}$. Nass et al., this conference, describe the conventional design of the source and the measurement of the jet density and polarization. Here we point out some of the unique features we believe are responsible for the record intensity of $12.4 \times 10^{16}$ atoms/s, significantly higher than the prediction of

* Work supported by United states department of Energy grant number DEFG02-88ER40438 
modeling codes $[1,2]$. We employed an improved if coupling in the dissociator and a pre-cooling of the dissociated gas before final thermal accommodation in the usual $2 \mathrm{~mm}$ diameter expansion nozzle cooled to 75K. More details are given in A. Zelenski et al., this conference. Large bore permanent 6-pole focussing magnets allow the beam to expand to $32 \mathrm{~mm}$ diameter over an unusually long $650 \mathrm{~mm}$ drift length before refocusing to a $5.8 \mathrm{~mm}$ FWHM target spot of $1.3 \pm 0.2 \times 10^{12}$ atoms $/ \mathrm{cm}^{2}$ thickness. The larger bore of the six-pole magnets implies both an increased gas conductance inside the magnets and a reduced beam density over much of the beam trajectory compared to other designs. These two factors may be responsible for a portion of the increased beam intensity.

\section{Magnetic field configuration}

The magnetic fields experienced by the atomic $\mathrm{H}$ beam are crucial for preservation of its nuclear polarization. To avoid non-adiabatic field changes we required that, in the atomic beam rest frame, the applied magnetic field direction may rotate no faster than $10^{-3 * *} \gamma_{\mathrm{L}}$, the Larmor precession rate $\left(\gamma_{\mathrm{p}} \mathrm{B}\right)$. Unfortunately, the target guide field configuration we employed to minimize the deflection of low energy $(<10 \mathrm{MeV})$ recoil protons resulted in two distinct locations where the field seen by the atomic beam reverses direction and strongly violates the adiabatic condition. Use of massive iron shielding allowed us to move the violation regions. In one case it was moved into the middle of a six-pole magnet and in the other into the field of a 2-4 rf transition. The transverse fields in these regions restored the adiabatic condition. Nass et al. this conference show that the residual depolarization is below $0.4 \%$.

\section{Vacuum}

The source is divided into 9 pumping stages, 6 for the beam formation and target region and 3 for the BRP (Breit-Rabi Polarimeter). We utilized two Varian 1000 liter/s turbo pumps $\left(2 \times 10^{6}\right.$ compression ratio for hydrogen) in each stage except for the first stage which has 3 pumps. Application of a fourth pump would achieve an intensity increase of $3.5 \%$. We achieved an operating pressure in the target region of $1.4 \times 10^{-8}$ Torr and a base (jet OFF) of $4 \times 10^{-9}$ Torr. 


\section{Breit-Rabi polarimeter}

The layout of the BRP is shown in figure 1. In the usual BRP polarization measurement all possible combinations of if transitions are used to solve for the fractional hyperfine occupation numbers. In our case it is sufficient to determine the efficiency of the two rf transitions located upstream of the interaction region. Furthermore it is possible to operate
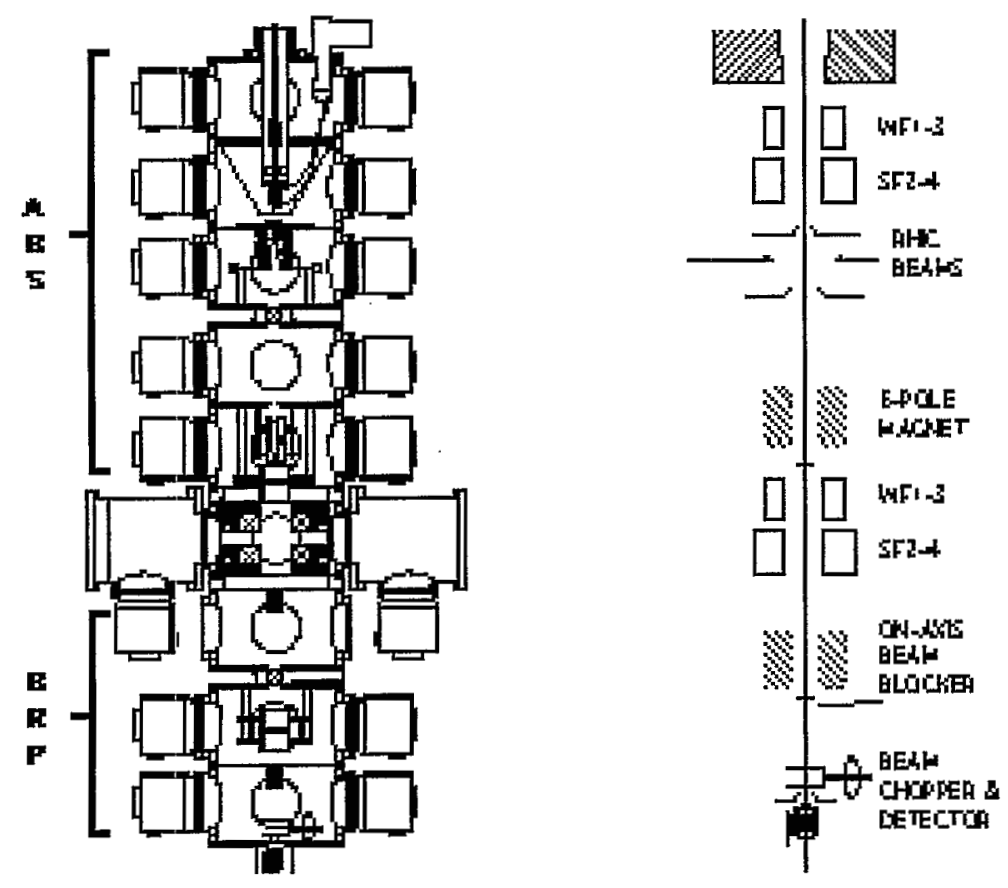

Figure 1. Left, the overall layout of the jet to scale. The third tubopump on the first stage and the massive iron shielding are not shown. The large centrally located chambers house silicon recoil detectors for calibration of the RHIC beam polarization. Right, the configuration of the lower portion of the jet assembly showing the arrangement of $\mathrm{tf}$ transitions, beam blockers, six-pole magnets and beam chopper. The BRP detector is a commercial ion gage biased with low ripple power supplies. 
the two upstream transitions simultaneously. If those transitions have $100 \%$ efficiency, no chopped beam should reach the BRP detector. The ideal situation is nearly realized for our setup. We observed a rate of 52 $\mathrm{Hz}$ in the detector with both upstream transitions on and a rate of about $20,900 \mathrm{~Hz}$ with the transitions off, leading to a lower limit to the average of the rf transition efficiencies of $99.7 \%$.

\section{Jet Polarization}

Even with perfect $\mathrm{rf}$ transition efficiency the Jet polarization will deviate from $100 \%$ because of several factors. At $0.12 \mathrm{~T}$ guide field, state 2 and 4 atoms have polarization $|\mathrm{P}|=0.921$ whereas state 1 and 3 atoms have $|\mathrm{P}|=1$, giving a two-state $(1+4$ or $2+3)$ theoretical $|\mathrm{Pmax}|=0.961$. In addition the jet beam includes a dilution of approximately $3 \%$ nucleons of unpolarized $\mathrm{H}_{2}$ gas measured with a QMA located at the RHIC beam interaction point. Although there was a possible depolarization from bunch field interaction with the circulating RHIC beam none was observed. Combining the above factors yields a jet polarization of $\mathrm{P}+=0.923 \pm 2 \%$ and $\mathrm{P}_{-}=-0.925 \pm 2 \%$. The difference between $\mathrm{P}+$ and $\mathrm{P}$ - is due to a small but consistent difference in the efficiency of the 1-3 and 2-4 $\mathrm{rf}$ transitions. The quoted errors are entirely dominated by the uncertainty in the molecular dilution. Construction and calibration of hardware for a more precise measurement of the molecular content of the jet is in progress.

\section{References}

1. T. Wise et al., Design of a polarized atomic H source for a Jet Target at RHIC. AIP Conference Proceedings 675, $15^{\text {th }}$ International Spin physics Symposium, Upton, NY, (2002), Yousef Makdisi, Alfredo U. Luccio, amd William W. MacKay eds.

2. A. Zelenski et al., Absolute Polarized H-Jet Polarimeter Development for RHIC, Proc. PST 2003, NIM A 26367 (2004). 